\title{
THE EPIPHANY: STUDENTS’ PERCEPTIONS OF MANAGEMENT AND TECHNICAL CONTENT IN A GRADUATE ANALYTICS COURSE
}

\author{
Michael Lohle, University of Bridgeport, mlohle@bridgeport.edu \\ Steven Terrell, Nova Southeastern University, terrell@nova.edu
}

\begin{abstract}
This case study focuses on student perceptions of managerial and technical content in a graduate analytics course taught at a small university. It describes this course's evolution from an exclusive focus on managerial content to a new version focused on both managerial and quantitative content. The findings indicate analytics students arrive with varied perspectives about the relative importance of managerial and technical content and emerge perceiving both as equally important. The study confirms appropriate instructional design can help ensure students appreciate the role of both management and technology in analytics.
\end{abstract}

Keywords: analytics, business intelligence, management, statistics, quantitative methods, SAS, pedagogy

\section{INTRODUCTION}

In the fall semester, 2019 the principal investigator (hereafter referred to as the "PI") taught an online business intelligence course focused exclusively on managerial content he had designed three years earlier. In the interim, he delivered the course on campus and added technical content and student engagement mechanisms that were never added online. As the PI taught the online version he was surprised how well his group of middle management students thrived on the managerial content. He initiated this case study to understand why his online students were so pleased with a course focused exclusively on managerial content while his on campus students, most of whom possessed minimal work experience, demanded technical content. This case study addressed these research questions:

- Does a student's work experience influence their interest in management content?

- Which engagement strategies help or hinder students' focus on the course's management content?

- What additional strategies should be considered to foster interest in managerial content in an analytics curriculum?

The answers led to an epiphany that triggered a fundamental course redesign balancing managerial, technical and statistical content. This paper discusses the case study's background, defines case studies, explains why this qualitative method was chosen and covers the findings, conclusions and recommendations for future research.

\section{Background}

The University of Bridgeport is a private institution in the state of Connecticut, United States. In 2014 School of Business leadership asked the PI to develop and implement an analytics concentration in the School of Business' Master of Business Administration. This three-course concentration consisted of a management course that introduced analytics, a course that introduced computer programming and a capstone course that introduced advanced statistical content. The PI met with business executives and leaders from the university's graduate technology management and computer science programs and conducted a competitive analysis of local graduate analytics programs. This triggered two observations. First, competing graduate analytics programs emphasized technical concepts. Second, since the university already offered technology management and computer science programs the school of business' opportunity focused on training business professionals to become "hybrid business-IT people" (Howson, 2014) who translate between information technology and business. After the analytics concentration was implemented student interest was sufficient to develop a full Master of Science in Analytics and Systems consisting of the three core courses described here and additional analytics and management courses. 
After implementing these programs the PI noticed analytics faculty tended to deemphasize management content in favor of technical content, defined here as statistics and computer programming. Students also believed technical skills enhanced their job prospects so they also emphasized technology. For instance, during the fall semester, 2019 the PI invited a business intelligence analyst from a local hospital to discuss his role. As he fielded questions, students aggressively grilled him about the technical tools required to land a job. Amid the crescendo the PI asked this guest lecturer, "What percentage of your role consists of technical content?" The guest lecturer confirmed only $20 \%$ of his average work day was spent using technology, the rest was spent engaging and communicating with coworkers and management. The dichotomy between this working practitioner's response and the university's faculty and student emphasis on technical concepts was striking.

\section{RESEARCH METHODOLOGY}

This case study explores the dichotomy between the guest lecturer's emphasis on communication and management and the students' and faculty's emphasis on technology. Creswell (2007) defined a case study as the exploration of an issue within a bounded system. The bounded system, or scope, of this case focuses on one graduate course the PI teaches called Enterprise Intelligence and Decision Support Systems. Picardi and Masick (2014) affirmed case studies focus on capturing data to address an issue during a specific time frame. This case study was approved by the university's Institutional Review Board for an initial survey conducted in the fall semester, 2019. A second survey was added during the spring semester, 2020 to assess student reactions to changes implemented in the course after the first survey's feedback. Sekaran (2003) confirms case studies provide a contextual analysis of a given situation. Students taking Enterprise Intelligence and Decision Support Systems are well into their graduate programs and are beginning their analytics studies.

\section{FINDINGS}

\section{First Survey, Fall Semester, 2019}

In December, 2019 the PI asked the sixteen students enrolled in graduate course Enterprise Intelligence and Decision Support Systems to respond a written survey presented via the Survey Monkey internet application that asked these questions:

- Do you have previous work experience?

Eleven students had previous work experience, five students did not have previous work experience.

- Do you consider management training important?

While 15 students responded "Yes," 1 responded "No."

- Do you consider technical training important?

All 16 students responded "Yes."

- Which option describes the relative importance of management and technical training?

Twelve students selected, "Management training and technical training are equally important."

Three students selected, "Management training is more important than technical training."

One student selected, "Technical training is more important than management training."

Responses that affirmed management training was more important than technical training included:

"That is the essence of work culture." 
"Management teaches much more vital skills needed to keep employees motivated, productive and committed to the company."

Responses that affirmed technical training was more important than managerial training emphasized students' job prospects:

“Technical skills are crucial in today's world and increase your chances of landing entry level jobs.”

"Technical training is the first step in getting the foot inside the door. The technical concepts are usually what employers are looking for."

"For most...students, technical training is more important...I think technical training is more important because the majority of students do not have any work experience."

Asked about the relative importance of managerial vs. technical training, 75\% of the students confirmed both were equally important.

“... you can be as technical as possible. But you have to [understand the] nuances of business and management practices to be a success."

“...the person has to know more about management, however technical is also important, it can weigh $60 \%$ to $40 \% . "$

"It helps to gain technical knowledge. A lot of businesspeople [lack this]."

"If you know how the technology works then you will be more likely to be promoted, yet if you know how to manage individuals and technology then you can make it to the top.”

The final two research questions focused on whether specific instructional design strategies would impact students' interest in managerial content:

- Which engagement strategies help or hinder students' focus on the course's management content?

- What additional strategies should be considered to foster interest in managerial content in an analytics curriculum?

To address this, the survey concluded with the following two questions and a relevant list of course activities:

- Which of these course activities was the most useful for your learning?

- Which of these course activities was the least useful for your learning?

Students confirmed the activities they found most useful and the activities they felt were less useful. As the PI assessed their feedback a faculty peer who taught a subsequent course in the analytics curriculum asserted students were arriving with insufficient statistics preparation and requested additional statistics content. Realizing accommodating this request while acknowledging the students' survey feedback would result in the removal of several course activities, the PI allocated time during the last class session to discuss all the feedback. The students strongly agreed with removing the activities they had confirmed were least useful and the request to include enhanced statistics content. This impromptu member checking, or reviewing qualitative feedback with study participants to confirm its accuracy, sent a strong message (Creswell, 2007). The PI streamlined the course and as the spring, 2020 semester began it consisted of two distinct pieces. The first focused on managerial content while the second provided an introduction to statistics and SAS Studio. SAS Studio was chosen because University of Bridgeport has an academic collaboration with The SAS Institute. The revised course content was implemented both on campus and online. 


\section{Second Survey, Spring Semester, 2020}

The PI delivered the new Enterprise Intelligence and Decision Support Systems course in the spring semester, 2020 with seven students enrolled. Six of the seven students responded to a second survey administered as the course finished in May, 2020 that contained these questions:

- Before you took this course which skill did you most associate with analytics?

- After taking this course which skill do you most associate with analytics?

- This course introduces both management topics about business intelligence and analytics and technical topics about statistics and SAS software. Did this combination work for you?

- Did the instructor do an effective job bridging the managerial and technical concepts of this course?

- After taking this course, how would you characterize your skills?

- What's the most important lesson you learned from this course?

Participants were evenly divided about the skill they most associated with analytics at the start of the course:

- $\quad$ Two students confirmed they had associated managerial skill with analytics.

- Two students confirmed they had associated technical skill with analytics.

- Two students had perceived both technical and managerial skill as equally important.

After taking the course all six respondents affirmed managerial and technical skill were equally important and said the combination of managerial and technical course content was effective.

Then the students confirmed the skills they came away with:

- $\quad$ Four attained foundational skills in both statistics and SAS.

- One attained foundational skills in SAS but none in statistics.

- One attained foundational skills in statistics but none in SAS.

While these results were encouraging, the PI found the students' response about emerging with SAS skills but no statistics skills and vice versa interesting since half the course emphasized both. Specific comments provide additional insight:

"Analytics is so much more than just the technical know-how. It is about managing data, technologies, people, etc. It also requires know[ledge of] the business unit, how they operate, what their processes are, what the data is used for, what they are looking to derive from the data, etc."

"I feel I was able to grasp the foundations of both statistics and SAS from this course. We covered some of the basic stats we'll see along the way in our careers. Funny - Chi Square and Correlation just came up yesterday at work...and I knew exactly what the CEO was talking about!”

“...I think $80 \%$ of the time, we need to understand the managerial concepts and with that, the $20 \%$ will come along. Therefore, this combination will make me one of the important employees in the company.”

"[The instructor] always begins with the business side and then he moved on with technical materials in SAS. For example, he taught me how to create [a] pie chart and analyze or explain how the chart gives value to someone (ex: managers).”

“...I learned a lot [in the] SAS homework and how to interpret them (pie chart, box plot etc.) in a business form.”

“...the way to run analysis in SAS and to turn our data into [a] visualization tool was amazing. I really enjoy playing with SAS.” 


\section{Issues in Information Systems}

Volume 21, Issue 2, pp. 144-149, 2020

\section{CONCLUSIONS}

Considerable analysis has been conducted to assess analytics program content. Aasheim, Williams, Rutner and Gardner (2015) focused on defining analytics and data science. Other studies, including a literature review published by Wang (2015) focused on highlighting gaps. Still others, including a study published by Chiang, Goes and Stohr (2012) sought to define relevant content. The research affirms analytics students require many skills to succeed, some unique to specific programs, some in common. For instance, Clayton and Clopton (2019) affirmed balancing statistical knowledge, programming skill and knowledge of finance and critical thinking, problem solving and communication are all critical. This emphasis on statistics is found across programs emphasizing varied fields from business to arts and sciences (Tate, 2017). Likewise, communication, creativity and teamwork are also recurring themes (PWC, 2018).

This case study discussed one PI's experience in understanding student perceptions of technical and managerial course content and acting upon their feedback and peer feedback to revise a graduate analytics course. Though this case study is not generalizable (Picardi \& Masick, 2014), it generated intriguing observations. For example, the PI noted previous work experience did not appear to impact student perspectives about managerial and technical course content. As interesting, students' perceptions about management and technology's importance varied before taking the new version of the course and they appreciated both afterward.

The quotes, "Funny - Chi Square and Correlation just came up yesterday at work...and I knew exactly what the CEO was talking about," and, "I really enjoy playing with SAS," are telling. Clearly this group of graduate analytics students enjoyed "playing" with technology and applying it to interpret data and they perceived business and management knowledge as beneficial for doing so. This revelation triggered an epiphany for the PI. Qualitative investigators should "bracket" their biases by stating them and confirming how to mitigate their impact (Creswell, 2007). The PI holds a Project Management Professional (PMP) certification from the Project Management Institute and has extensive management experience. As a result, previous versions of the Enterprise Intelligence and Decision Support Systems course focused on management. Perhaps this was a manifestation of the PI's bias and surveying his students and acting upon their requests and similar requests from faculty for additional quantitative content served to "bracket" this bias. As the spring semester closed, all that was missing was industry validation for the changes the PI implemented. As if on cue, in April, 2020 a large, local bank called to discuss potential internships. Without prompting the caller said the bank needed analytics students with strong business, statistics and SAS skills. Though this conversation was not related to this case study it provided impromptu industry feedback that aligned with this case study's student and faculty feedback.

\section{RECOMMENDATIONS FOR FUTURE RESEARCH}

Expanding this research across the University of Bridgeport's analytics courses and including courses at additional colleges and universities would be beneficial. Likewise, conducting a grounded theory study to establish a model for subsequent testing would help. In addition, asking industry practitioners to confirm content that should be taught in analytics courses would build upon the bank's feedback and add more gravitas. Moreover, this case study assumed analytics equates with the business interpretation of data using statistics and software tools, specifically SAS Studio. The Enterprise Intelligence and Decision Support Systems course also explores management concepts including the information technology and business relationship, data governance, master data management, project management and quality assurance. Studying whether such topics should play an expanded role in analytics curricula would be helpful. Finally, this case study made no attempt to distinguish analytics from data science and the perspectives of analytics and data science students and faculty about the relative importance of managerial and technical content may differ. These are all interesting avenues for further exploration.

\section{REFERENCES}

Aasheim, C. L., Williams, S., Rutner, P., \& Gardiner, A. (2015). Data analytics vs. data science: A study of similarities and differences in undergraduate programs based on course descriptions. Journal of Information Systems Education, 26(2), 103 - 115. 
Chiang, R. H., Goes, P., \& Stohr, E. A. (2012). Business intelligence and analytics education, and program development: A unique opportunity for the information systems discipline. ACM Transactions on Management Information Systems, 3(3).

Clayton, P. R. \& Clopton, J. (2019). Business curriculum redesign: Integrating data analytics. Journal of Education for Business, 94(1), $57-63$.

Creswell, J. W. (2007). Qualitative Inquiry and Research Design, Choosing Among Five Approaches. Thousand Oaks, CA: Sage Publications, Inc.

Howson, C. (2014). Successful Business Intelligence (Second ed.). New York, NY: McGraw Hill Education.

Picardi, C. A., \& Masick, K. D. (2014). Research Methods, Designing and Conducting Research With a Real-World Focus. Thousand Oaks, CA: Sage Publications, Inc.

PWC. (2018) What's next for the data science and analytics job market? Retrieved from https://www.pwc.com/us/en/library/data-science-and-analytics.html.

Sekaran, U. (2003). Research Methods for Business, A Skill Building Approach (Fourth ed.). Hoboken, NJ: John Wiley \& Sons, Inc.

Tate, E. (2017). Data analytics programs take off. Inside Higher Ed. https://www.insidehighered.com/digitallearning/article/2017/03/15/data-analytics-programs-taking-colleges

Wang, Y. (2015). Business intelligence and analytics education: Hermeneutic literature review and future directions in IS education. Twenty-first Americas Conference on Information Systems. Puerto Rico. 